\title{
Acute and Short-term Effects of Secondhand Smoke on Lung Function and Cytokine Production
}

\author{
Andreas D. Flouris', Giorgos S. Metsios², Andres E. Carrillo', Athanasios Z. Jamurtas 1,3, \\ Konstantinos Gourgoulianis 4 , Theodoros Kiropoulos ${ }^{4}$, Manolis N. Tzatzarakis ${ }^{5}$, \\ Aristidis M. Tsatsakis ${ }^{5}$, and Yiannis Koutedakis ${ }^{1,2,3}$
}

\begin{abstract}
${ }^{1}$ Institute of Human Performance and Rehabilitation, Centre for Research and Technology-Thessaly, Trikala, Greece; ${ }^{2}$ School of Sports, Performing Arts and Leisure, University of Wolverhampton, Wolverhampton, United Kingdom; ${ }^{3}$ Department of Sport and Exercise Science, University of Thessaly, Trikala, Greece; ${ }^{4}$ Department of Respiratory Medicine, University Hospital of Larissa, Larissa, Greece; and ${ }^{5}$ Centre of Toxicology Science and Research, School of Medicine, University of Crete, Iraklio, Greece
\end{abstract}

Rationale: The acute effect of secondhand smoke (SHS) on lung function and the duration of system disruption remain unknown. Objectives: To assess the SHS effects and their duration on lung function and inflammatory markers.

Methods: In a randomized single-blind crossover experiment data were obtained from 16 (8 women) nonsmoking adults at baseline and at 0,1 , and 3 hours after a 1-hour SHS exposure set at bar/ restaurant SHS levels.

Measurements and Main Results: Serum and urine cotinine, lung function, and cytokines IL-4, IL-5, IL-6, tumor necrosis factor (TNF)$\alpha$, and IFN- $\gamma$. At 0 hours most lung function parameters were significantly reduced (indicative: $\mathrm{FEV}_{1}, 4.3 \pm 0.4$ vs. $3.8 \pm 0.3 \mathrm{~L}$; $\mathrm{FEV}_{1} / \mathrm{FVC}, 0.9 \pm 0.1$ vs. $\left.0.8 \pm 0.1 ; P<0.05\right)$ but at 3 hours they were at baseline levels. In contrast, cotinine (serum, $8.9 \pm 3.2$ vs. $35.5 \pm$ $\left.10.2 \mathrm{ng} \cdot \mathrm{ml}^{-1}\right), \mathrm{IL}-4\left(41.3 \pm 5.8 \mathrm{vs} .44 .2 \pm 4.5 \mathrm{pg} \cdot \mathrm{ml}^{-1}\right), \mathrm{IL}-5(36.1 \pm$ 3.2 vs. $\left.60.1 \pm 7.0 \mathrm{pg} \cdot \mathrm{ml}^{-1}\right), \mathrm{IL}-6\left(2.5 \pm 0.3 \mathrm{vs} .7 .6 \pm 1.4 \mathrm{pg} \cdot \mathrm{ml}^{-1}\right)$ and IFN- $\gamma\left(0.3 \pm 0.2\right.$ vs. $\left.0.6 \pm 0.2 \mathrm{IU} \cdot \mathrm{ml}^{-1}\right)$ at 3 hours were higher than at baseline $(P<0.05)$. IL-4 and TNF- $\alpha$ increased only in men, whereas IL-5, IL-6, and IFN- $\gamma$ were different between sexes after exposure $(P<0.05)$. Regression analyses revealed inverse associations of $F E V_{1}$ and $\mathrm{FEV}_{1} / \mathrm{FVC}$ ratio with IL-5 $(P<0.05)$ in men and with IL-5 $(P=0.01)$, IL-6 $(P<0.001)$, IFN- $\gamma(P=0.034)$ and serum cotinine $(P<0.001)$ in women.

Conclusions: We conclude that 1 hour of SHS exposure at bar/ restaurant levels is accompanied by significant decrements on lung function and marked increases in inflammatory cytokines, particularly in men. More importantly, whereas most smoke-induced effects on lung function appear to recede within $\mathbf{6 0}$ minutes, inflammatory cytokines remain elevated for at least 3 hours after exposure to SHS.

Keywords: passive smoking; cotinine; respiration; inflammatory markers

In the 10 minutes you will spend reading this article, 111 people will die somewhere in the world from tobacco-induced illnesses.* Fourteen of them have never smoked.$^{\dagger}$

An overwhelming amount of evidence has emerged over the past decades on the adverse health effects of secondhand smoke

(Received in original form December 21, 2008; accepted in final form March 4, 2009) * Approximation based on 5 million per annum tobacco-induced global mortality $(4,36)$.

${ }^{\dagger}$ Approximation based on 79 thousand per annum SHS-induced deaths in Europe (37).

Correspondence and requests for reprints should be addressed to Andreas D. Flouris, Ph.D., Institute of Human Performance and Rehabilitation, Centre for Research and Technology-Thessaly, 32 Siggrou Street, Trikala GR42100, Greece. E-mail: aflouris@cereteth.gr

This article has an online supplement, which is accessible from this issue's table of contents at www.atsjournals.org

Am J Respir Crit Care Med Vol 179. pp 1029-1033, 2009

Originally Published in Press as DOI: 10.1164/rccm.200812-19200C on March 5, 2009

Internet address: www.atsjournals.org

\section{AT A GLANCE COMMENTARY}

Scientific Knowledge on the Subject

Epidemiological studies have identified the long-term detrimental consequences of secondhand smoke (SHS), but the acute SHS effects and their duration, as well as the underlying physiological mechanisms, remain unexplored.

\section{What This Study Adds to the Field}

A 1-hour moderate SHS exposure is accompanied by significantly deteriorated lung function and marked increases in inflammatory cytokines, particularly in men. Although most SHS-induced effects on lung function appear to recede within 60 minutes, inflammatory cytokines remain elevated for at least 3 hours following SHS exposure.

(SHS) (1-5). Nevertheless, more than 126 million American and 130 million Chinese adult nonsmokers suffer daily SHS exposure, whereas global estimates include 700 million children and 50 million pregnant women (1). Latest reports show that, despite current measures, the prevalence rates of smoking are increasing $(2,3)$, while the tobacco industry predicts a global expansion of the tobacco epidemic in the near future (3). Moreover, arguments are being expressed that only chronic exposures to SHS represent a health risk and that there is no scientific basis for claims that brief, acute, transient SHS exposures represent a significant acute health hazard in nonsmokers (6). This is, in part, because our knowledge on the effects of SHS is based predominantly on longitudinal epidemiological studies, whereas experimental studies assessing the acute and short-term effects of SHS are scarce. Yet, the latter are essential and, comparatively, more important in elucidating the underlying physiological mechanisms involved in SHSinduced system disruption $(7,8)$.

Chronic lung disease is generally the result of long-term processes, yet, even brief SHS exposures appear to initiate mechanisms that contribute to its development. For instance, shortly after the beginning of smoke exposure there is a rapid and marked up-regulation of growth factor production as well as production of type 1 procollagen in the small airways (9). Furthermore, spontaneous inhalation of cigarette smoke elicits acute pulmonary chemoreflexes, characterized by apnea, bradycardia, and hypotension through activation of pulmonary $\mathrm{C}$ fibers (10). These findings are in line with experimental data from our (11-14) and other (15-17) laboratories showing that even brief SHS exposures generate unfavorable changes in various cardiovascular, endocrine, and immune mechanisms. Additionally, human (12) and animal (18) models suggest an 


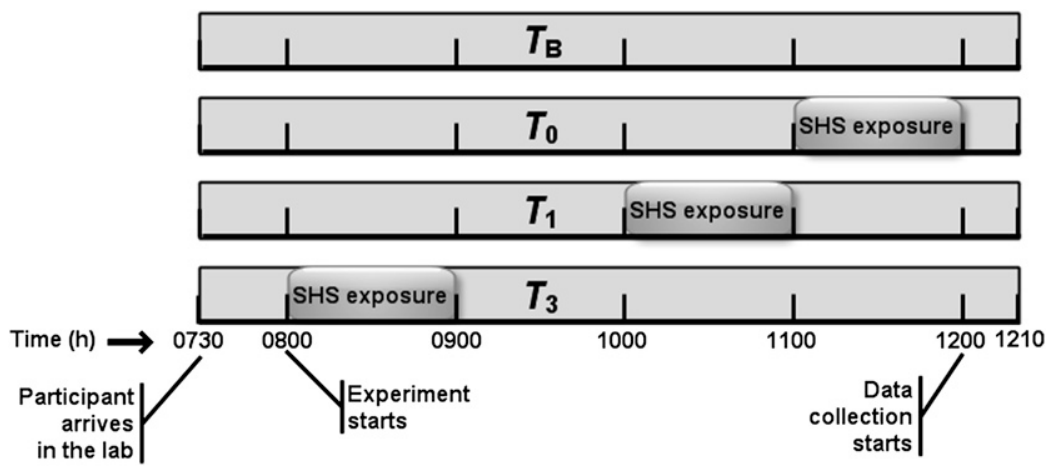

Figure 1. Overview of the experimental design: In the baseline trial $\left(T_{\mathrm{B}}\right)$ participants' data were collected at 1200 hours without any secondhand smoke (SHS) exposure. In the remaining trials, participants were exposed to SHS for 1 hour either at 0800 hours $\left(T_{3}\right), 1000$ hours $\left(T_{1}\right)$ or at 1100 hours $\left(T_{0}\right)$, while data were collected at 1200 hours. SHS = secondhand smoke. association between SHS exposure and elevated proinflammatory cytokines, which may be linked to the development and/or exacerbation of chronic lung disease. However, the precise effects of SHS on the respiratory system and cytokine production remain elusive. Given the role of inflammation in the development of impaired respiratory function, understanding the acute SHS-induced respiratory and immune responses is crucial (19) because SHS is associated with an increased prevalence of chronic lung diseases and allergies (20). Notably, the duration of system disruption after brief SHS exposures has yet to be elucidated. We conducted a randomized single-blind crossover experiment to assess lung function and cytokine responses before as well as 0,1 , and 3 hours after a 1-hour moderate exposure to SHS.

\section{METHODOLOGY}

\section{Participants and Procedures}

The experimental protocol was approved by the ethical review board at the University of Thessaly. Sixteen healthy adults (8 men, 8 women, aged $27.2 \pm 4.3 \mathrm{yr}$; body mass index, $22.0 \pm 1.8$ ) volunteered. Exclusion criteria included smoking, pregnancy, evidence of cardiac or pulmonary disease, and previous disease and medications known to affect lung function. All women participants were premenopausal with regular menstruation and were tested during the late luteal phase of their menstrual cycle.

\section{Experimental Design}

Participants visited the laboratory at 0730 hours for four trials conducted in a random order and separated by 7 days. In the baseline trial $\left(T_{\mathrm{B}}\right)$ participants were assessed for cotinine, lung function, and cytokine levels without any SHS exposure precisely at 1200 hours. In the remaining trials, participants were exposed to SHS for 1 hour either at 0800 hours $\left(T_{3}\right), 1000$ hours $\left(T_{1}\right)$, or at 1100 hours $\left(T_{0}\right)$, while cotinine, lung function, and cytokine levels were assessed at 1200 hours as illustrated in Figure 1. See the online supplement for further details.

All testing was conducted by the same trained investigators, who were unaware of the specific trial each participant was undergoing. To ensure that the investigators would not be able to differentiate between trials, participants were given a shirt and athletic pants to wear upon exiting the chamber after all trials. These clothes had been previously exposed to SHS inside the chamber and emitted a strong tobacco scent.

The present is a new experiment, yet methods regarding the SHS exposure as well as measurements for serum and urine cotinine and cytokine production have been used previously in our laboratory and are described in detail elsewhere $(11,12)$. Further detail on the method for making these measurements is provided in the online supplement.

\section{Lung Function}

$\mathrm{FVC}, \mathrm{FEV}_{1}, \mathrm{FEV}_{1} / \mathrm{FVC}$ ratio, peak expiratory flow (PEF), as well as maximum expiratory flow (MEF) when $75 \%, 50 \%$ and $25 \%$ of $\mathrm{FVC}$ remains in the lungs $\left(\mathrm{MEF}_{75 \%}, \mathrm{MEF}_{50 \%}\right.$, and $\mathrm{MEF}_{25 \%}$, respectively) were measured using a hand-held spirometer (Spiromed 180, Fukuda Sangyo, Pulmonary Products, Tokyo, Japan) calibrated before each use. The lung function assessment protocol conformed to the American Thoracic Society recommendations (21).

\section{Statistical Analysis}

Given the significant sexual dimorphism in the acute SHS effects (12), participants' data were divided by sex into groups. A twogroup (men, women) by four-times $\left(T_{\mathrm{B}}, T_{0}, T_{1}\right.$ and $\left.T_{3}\right)$ factorial analysis of variance (ANOVA), followed by sex-specific post-hoc $t$ tests incorporating a Bonferroni adjustment, was used to assess the effect of sex and time after SHS on all the examined variables. Given the statistically significant effect of SHS on $\mathrm{FEV}_{1}$ and the $\mathrm{FEV}_{1} / \mathrm{FVC}$ ratio (see RESUlTs), sex-specific stepwise multiple linear regression analyses incorporating backward elimination at the $P<0.05$ level were introduced to model the effect of cotinine and cytokine concentrations (independent variables) on these lung function parameters (dependent variables). The level of significance was set at $P<0.05$ except for post-hoc tests in which a Bonferroni adjustment was applied. Additional detail on the statistical analyses is provided in the online supplement.

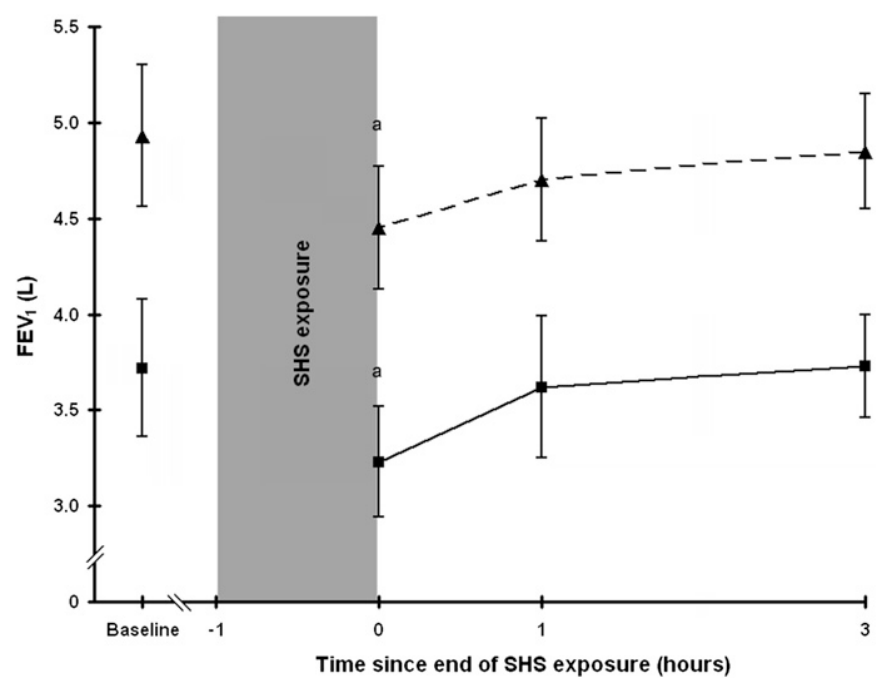

Figure 2. Mean $\pm \mathrm{SD}$ of $\mathrm{FEV}_{1}$ for men (triangles) and women (squares) in each trial. Values dropped $9.7 \%$ in men and $13.2 \%$ in women between $T_{\mathrm{B}}$ and $T_{0} . \mathrm{a}=$ significant $(P<0.05)$ difference from previous trial (timepoint). 
TABLE 1. LUNG FUNCTION AND TIME COMPARISONS FOR MEN AND WOMEN IN EACH TRIAL

\begin{tabular}{|c|c|c|c|c|c|}
\hline & & $T_{\mathrm{B}}$ & $T_{0}$ & $T_{1}$ & $T_{3}$ \\
\hline \multirow[t]{2}{*}{ FVC, L } & M & $6.0 \pm 0.7$ & $6.0 \pm 0.7$ & $6.0 \pm 0.8$ & $5.9 \pm 0$. \\
\hline & W & $4.0 \pm 0.6$ & $4.0 \pm 0.6$ & $4.0 \pm 0.5$ & $4.1 \pm 0$. \\
\hline \multirow[t]{2}{*}{$\mathrm{FEV}_{1}, \mathrm{~L}$} & M & $4.9 \pm 0.4$ & $4.5 \pm 0.3^{*}$ & $4.7 \pm 0.3$ & $4.9 \pm 0.3$ \\
\hline & W & $3.7 \pm 0.4$ & $3.2 \pm 0.3^{*}$ & $3.6 \pm 0.4$ & $3.7 \pm 0.3$ \\
\hline \multirow[t]{2}{*}{$\mathrm{FEV}_{1} / \mathrm{FVC}$} & M & $0.8 \pm 0.1$ & $0.7 \pm 0.1^{*}$ & $0.8 \pm 0.1$ & $0.8 \pm 0.1$ \\
\hline & W & $0.9 \pm 0.1$ & $0.8 \pm 0.1^{*}$ & $0.9 \pm 0.1^{*}$ & $0.9 \pm 0.1$ \\
\hline \multirow[t]{2}{*}{ PEF, L.sec ${ }^{-1}$} & M & $9.8 \pm 0.7$ & $9.5 \pm 0.3$ & $9.6 \pm 1.0$ & $9.7 \pm 0.9$ \\
\hline & W & $7.8 \pm 1.2$ & $7.8 \pm 1.2$ & $8.1 \pm 0.9$ & $8.1 \pm 0.9$ \\
\hline \multirow[t]{2}{*}{$\mathrm{MEF}_{75 \%}, \mathrm{~L} \cdot \mathrm{sec}^{-1}$} & M & $8.0 \pm 0.3$ & $6.9 \pm 0.4^{*}$ & $6.9 \pm 0.6^{\dagger}$ & $7.3 \pm 0.7$ \\
\hline & W & $6.6 \pm 0.4$ & $6.0 \pm 0.3^{*}$ & $6.3 \pm 0.3$ & $6.4 \pm 0.4$ \\
\hline \multirow[t]{2}{*}{$\mathrm{MEF}_{50 \%}, \mathrm{~L} \cdot \mathrm{sec}^{-1}$} & M & $5.8 \pm 0.5$ & $4.7 \pm 0.5^{*}$ & $4.7 \pm 0.8^{\dagger}$ & $5.2 \pm 0.9$ \\
\hline & W & $4.7 \pm 0.3$ & $4.1 \pm 0.1^{*}$ & $4.4 \pm 0.3$ & $4.6 \pm 0.3$ \\
\hline \multirow[t]{2}{*}{$\mathrm{MEF}_{25 \%}, \mathrm{~L} \cdot \mathrm{sec}^{-1}$} & M & $2.8 \pm 0.3$ & $2.4 \pm 0.3^{*}$ & $2.5 \pm 0.3$ & $2.6 \pm 0.3$ \\
\hline & W & $3.1 \pm 0.5$ & $2.7 \pm 0.2$ & $2.7 \pm 0.3$ & $3.0 \pm 0.3$ \\
\hline
\end{tabular}

Definition of abbreviations: $\mathrm{M}=$ men; $\mathrm{MEF}_{75 \%}, \mathrm{MEF}_{50 \%}, \mathrm{MEF}_{25 \%}$ : maximum expiratory flow when $75 \%, 50 \%$ and $25 \%$ of $\mathrm{FVC}$ remains in the lungs, respectively; $\mathrm{PEF}=$ peak expiratory flow; $\mathrm{TB}=$ time at baseline; $T_{0}, T_{1}, T_{3}=$ time at 0,1 , and 3 hours, respectively; $\mathrm{W}=$ women.

Values are mean $\pm \mathrm{SD}$. All sex-comparisons were significant at $P<0.05$ except $\mathrm{MEF}_{50 \%}$ at $T_{1}$ and $T_{3}$ and $\mathrm{MEF}_{25 \%}$ at $T_{\mathrm{B}}$ and $T_{1}$.

* Significant difference from previous trial (time-point); $P<0.05$.

+ Significant difference of $T_{1}$ and $T_{3}$ from $T_{\mathrm{B}} ; P<0.05$.

\section{RESULTS}

The factorial ANOVA $\left(\mathrm{R}^{2}=0.799 ;{ }_{\text {adj }} \mathrm{R}^{2}=0.774\right)$ revealed that the values of all variables except FVC $(P=0.999)$, PEF $(P=$ $0.889)$, and IL-4 $(P=0.079)$ changed depending on the time of measurement (significant main effect: $\mathrm{F}_{(36,141)}=6.687 ; P<$ $0.001)$. The same analysis also showed that the values of all variables except IL-4 $(P=0.218)$ were different between sexes (significant main effect: $\mathrm{F}_{(12,45)}=35.488, P<0.001$ ). Furthermore, the aforementioned time-induced changes in cotinine, lung function, and cytokines were not the same for men and women (significant interaction effect: $\mathrm{F}_{(36,141)}=2.127 ; P=0.001$ ). For instance, IL-4 and tumor necrosis factor (TNF)- $\alpha$ increased after the SHS exposure only in men $(P<0.05)$, whereas in women there was no change across time $(P>0.05)$.

As expected, the sex-specific post-hoc $t$ tests (Figure 2 and Tables 1 and 2) demonstrated an effect of SHS on pulmonary function characterized by an acute response at $T_{0}$ that was attenuated with longer exposure lags $\left(T_{1}\right.$ and $\left.T_{3}\right)$. Specifically, although at $T_{0}$ the values of $\mathrm{FEV}_{1}, \mathrm{FEV}_{1} / \mathrm{FVC}$ ratio, $\mathrm{MEF}_{75 \%}$, $\mathrm{MEF}_{50 \%}$ and $\mathrm{MEF}_{25 \%}$ were markedly reduced $(P<0.05)$, at $T_{3}$ they were at levels similar to $T_{\mathrm{B}}(P>0.05)$. In contrast, mean values at $T_{3}$ of cotinine levels and all inflammatory markers except TNF- $\alpha$ remained higher than $T_{\mathrm{B}}$ levels $(P<0.05)$. Notably, in some cases (e.g., IL-4, IL-6, and IFN- $\gamma$ ) the effect of SHS increased with greater lag.

The stepwise multiple linear regression analyses for $\mathrm{FEV}_{1}$ demonstrated an inverse association with IL-5 $(\beta=-0.007 ; P=$ $0.05)$ in men $\left(\mathrm{R}^{2}=0.339 ; \mathrm{F}_{(1,30)}=3.886 ; P=0.05\right)$ as well as inverse associations with IL-6 $(\beta=-0.16 ; P<0.001)$ and serum cotinine $(\beta=-0.025 ; P<0.001)$ in women $\left(\mathrm{R}^{2}=0.645 ; \mathrm{F}_{(3,28)}=6.661 ; P=\right.$ $0.002)$. The same analysis for $\mathrm{FEV}_{1} / \mathrm{FVC}$ ratio revealed an inverse association with IL-5 $(\beta=-0.002 ; P=0.022)$ in men $\left(\mathrm{R}^{2}=0.41\right.$; $\left.\mathrm{F}_{(2,29)}=2.931 ; P=0.05\right)$ as well as inverse associations with IL-5 $(\beta=-0.003 ; P=0.01)$ and $\operatorname{IFN}-\gamma(\beta=-0.144 ; P=0.034)$ in women $\left(\mathrm{R}^{2}=0.47, \mathrm{~F}_{(2,29)}=4.102 ; P=0.027\right)$.

\section{DISCUSSION}

To the best of our knowledge, this is the first experiment to investigate the duration of the acute SHS effects on lung
TABLE 2. COTININE CONCENTRATIONS, CYTOKINE LEVELS, AND TIME COMPARISONS FOR MEN AND WOMEN IN EACH TRIAL

\begin{tabular}{|c|c|c|c|c|c|}
\hline & & $T_{\mathrm{B}}$ & $T_{0}$ & $T_{1}$ & $T_{3}$ \\
\hline \multirow{2}{*}{$\begin{array}{l}\text { Serum cotinine, } \\
\mathrm{ng} \cdot \mathrm{mL}^{-1}\end{array}$} & M & $8.5 \pm 2.5$ & $27.4 \pm 12.1^{*}$ & $39.9 \pm 14.1^{\dagger}$ & $38.0 \pm 10.1^{\dagger}$ \\
\hline & W & $9.3 \pm 3.6$ & $21.8 \pm 8.3^{*}$ & $35.6 \pm 9.7^{* \dagger}$ & $32.9 \pm 10.3^{\dagger}$ \\
\hline \multirow{2}{*}{$\begin{array}{l}\text { Urine cotinine, } \\
\mathrm{ng} \cdot \mathrm{ml}^{-1}\end{array}$} & M & $6.4 \pm 2.2$ & $21.1 \pm 10.6$ & $29.6 \pm 13.0^{\dagger}$ & $29.4 \pm 13.8^{\dagger}$ \\
\hline & W & $7.9 \pm 3.3$ & $22.0 \pm 8.3^{*}$ & $30.5 \pm 8.8^{\dagger}$ & $28.3 \pm 10.5^{\dagger}$ \\
\hline \multirow[t]{2}{*}{$\mathrm{IL}-4, \mathrm{pg} \cdot \mathrm{ml}^{-1}$} & $M$ & $44.9 \pm 3.5^{\ddagger}$ & $49.6 \pm 4.3^{*}$ & $46.4 \pm 4.5$ & $47.0 \pm 4.6^{\dagger *}$ \\
\hline & W & $37.7 \pm 6.4^{\ddagger}$ & $43.8 \pm 5.3$ & $43.3 \pm 6.1$ & $41.4 \pm 4.3^{\ddagger}$ \\
\hline \multirow[t]{2}{*}{$\mathrm{IL}-5, \mathrm{pg} \cdot \mathrm{ml}^{-1}$} & M & $37.2 \pm 6.8$ & $69.7 \pm 7.5^{* \neq}$ & $79.7 \pm 5.2^{\star \dagger \ddagger}$ & $65.7 \pm 5.8^{* \dagger \neq}$ \\
\hline & W & $35.1 \pm 1.4$ & $56.0 \pm 8.0^{\star \ddagger}$ & $66.4 \pm 2.6^{\star \dagger \ddagger}$ & $54.5 \pm 7.6^{*+t}$ \\
\hline \multirow[t]{2}{*}{$\mathrm{IL}-6, \mathrm{pg} \cdot \mathrm{ml}^{-1}$} & M & $2.4 \pm 0.3$ & $6.4 \pm 2.5^{\star}$ & $8.2 \pm 1.3^{\dagger}$ & $9.0 \pm 1.5^{\dagger \neq}$ \\
\hline & W & $2.5 \pm 0.4$ & $5.8 \pm 1.9^{*}$ & $7.4 \pm 1.2^{\dagger}$ & $6.3 \pm 1.1^{\text {t⿱ }}$ \\
\hline \multirow[t]{2}{*}{$\mathrm{TNF}-\alpha, \mathrm{pg} \cdot \mathrm{ml}^{-1}$} & M & $9.3 \pm 1.6^{\ddagger}$ & $12.4 \pm 2.4^{\star \ddagger}$ & $11.2 \pm 2.1^{\ddagger}$ & $8.4 \pm 0.9^{* \neq}$ \\
\hline & W & $6.4 \pm 1.5^{\ddagger}$ & $8.0 \pm 2.2^{\mathrm{d}}$ & $7.4 \pm 1.8^{\ddagger}$ & $6.4 \pm 1.2^{\ddagger}$ \\
\hline \multirow[t]{2}{*}{$\mathrm{IFN}-\gamma, \mathrm{IU} \cdot \mathrm{ml}^{-1}$} & M & $0.3 \pm 0.2$ & $0.6 \pm 0.2^{\star \ddagger}$ & $0.8 \pm 0.2^{\dagger \neq}$ & $0.7 \pm 0.1^{\dagger \neq}$ \\
\hline & W & $0.3 \pm 0.1$ & $0.4 \pm 0.1^{\ddagger}$ & $0.6 \pm 0.2^{\dagger \neq}$ & $0.5 \pm 0.2^{\dagger \neq}$ \\
\hline
\end{tabular}

Definition of abbreviations: $\mathrm{M}=$ men; $\mathrm{TB}=$ time at baseline; $\mathrm{T}_{0}, \mathrm{~T}_{1}, \mathrm{~T}_{3}=$ time at 0,1 , and 3 hours, respectively; TNF- $\alpha$ : tumor necrosis factor- $\alpha ; W=$ women.

Values are mean \pm SD

* Significant difference from previous trial (time-point); $P<0.05$.

${ }^{\dagger}$ Significant difference of $T_{1}$ and $T_{3}$ from $T_{\mathrm{B}} ; P<0.05$.

\# Significant difference between sexes for the same measurement; $P<0.05$.

function and cytokine levels. Our results demonstrated that 1 hour of moderate SHS exposure generates significant decrements on lung function and marked increases in the vast majority of the cytokines investigated. More important, whereas most SHS-induced effects on lung function appear to recede within 60 minutes, inflammatory cytokines remain elevated for at least 3 hours after exposure.

Previous epidemiological studies have shown that chronic SHS is associated with a reduction of several lung function measures, yet these findings have not been consistent, and methodological issues have constrained interpretation of the findings (22). The present data show clearly a significant effect of acute SHS on $\mathrm{FEV}_{1}, \mathrm{FEV}_{1} / \mathrm{FVC}$ ratio, $\mathrm{MEF}_{75 \%}, \mathrm{MEF}_{50 \%}$, and $\mathrm{MEF}_{25 \%}$. The SHS-induced changes in $\mathrm{FEV}_{1}$ and $\mathrm{FEV}_{1} /$ FVC ratio resemble closely the airway obstruction apparent in smokers (23), although the present $\mathrm{FEV}_{1} / \mathrm{FVC}$ ratio at $T_{0}$ was 0.74 and not 0.70 . This notion is further supported by the SHSinduced changes in $\mathrm{MEF}_{75 \%}, \mathrm{MEF}_{50 \%}$, and $\mathrm{MEF}_{25 \%}$, which show a MEF-volume curve convex to the volume axis with an increasing curve in late expiration. These results are typical for obstructive diseases like cystic fibrosis, bronchial asthma, and wheezy bronchitis (24). Furthermore, our findings confirm a previous epidemiological study suggesting that acute SHS was associated with symptoms of chronic bronchitis (25).

The mechanism underlying the airflow limitation observed immediately after the SHS exposure (i.e., $T_{0}$ ) may be related to SHS-induced airway irritation. Previous research has shown that cigarette smoke inhalation elicits irregular breathing patterns, cough reflex, and bronchoconstriction through activation of vagal afferents (26). On the other hand, recent evidence suggests that SHS induces rapid profibrotic growth factor production in the walls of small airways through an oxidant mechanism (9). These findings suggest that the initial response to cigarette smoke may reflect direct induction of growth factors resulting in airway remodeling. Fibrosis and thickening of the airway wall, particularly in the subepithelial compartment in the small airways, are an important part of the pathogenesis of SHS-induced airflow limitation, yet the precise effect of airway remodeling type on airflow obstruction remains to be determined (9). 
The observed SHS-induced increase in circulating inflammatory markers extends the findings of a small number of previous human experiments reporting SHS-induced increases of IL-1 $\beta$ (12), white blood cell count, C-reactive protein, homocysteine, fibrinogen (17), as well as leukocyte counts accompanied by an activation of the immune cells (27). The present results also confirm another study by our group reporting an increased SHS-induced inflammatory reaction in men compared with women (12). In the present experiment we found that IL-4 and $\mathrm{TNF}-\alpha$ increased only in men, while there was significant sexual difference in IL-5, IL-6 and IFN- $\gamma$ after SHS exposure.

Given that the cytokines investigated are closely associated with the chronic lung inflammation and structural changes observed in pulmonary disease patients (28), it could be suggested that chronic SHS may have clinical implicationsespecially in men, given their increased inflammatory response-such as increased susceptibility to infection, chronic lung inflammation, as well as pathological airway changes including chronic obstructive pulmonary diseases. The present concentrations of IL-5, IL-6, and IFN- $\gamma$ after SHS exposure were linked with the marked decreases in $\mathrm{FEV}_{1}$ and $\mathrm{FEV}_{1} / \mathrm{FVC}$ ratio, confirming the association between circulating inflammation markers and $\mathrm{FEV}_{1}$ (29). In turn, lower $\mathrm{FEV}_{1}$ and $\mathrm{FEV}_{1} /$ FVC ratio are associated with a greater prospective risk of cardiovascular mortality among nonsmokers (22). The current finding that inflammatory cytokine levels remain elevated for at least 3 hours after SHS exposure alludes to chronic low-grade systemic inflammation in individuals exposed to SHS on a daily basis and/or at higher smoke concentrations. This is particularly true for IFN- $\gamma$, which is closely linked with chronic obstructive pulmonary disease and asthma (30). At present, the physiological mechanisms linking low-grade systemic inflammation and pulmonary disease is not entirely understood (31). However, a number of studies have reported higher levels of systemic fibrinogen and C-reactive protein in individuals with impaired lung function (32) and in patients suffering from chronic obstructive pulmonary disease (33).

Prosmoking groups use the reduced sales of tobacco products in selected few countries to argue that smoking bans are not necessary. This delusion is accompanied by an equally pernicious myth that there is "no scientific basis for claims that brief, acute, transient exposure to secondhand smoke...represents any other significant acute...health hazard in nonsmokers" (6). Several studies referenced in the present article reject this argument. In fact, to our knowledge, all human exposure studies investigating the acute effects of SHS have reported significant detrimental results. With regard to the present experiment, it is important to note that the observed changes in lung function and inflammatory cytokines did not arise from an extreme and/or prolonged SHS exposure. The reported cotinine levels suggest a moderate and brief SHS exposure (34) confirming a successful simulation of a bar/restaurant smoking environment. Further, it is not possible that the comparatively long half-life of cotinine, the diurnal variation in lung function and inflammatory markers, or the investigators' expectations were reflected in our results. This is because the adopted design enabled data collection without SHS exposure $\left(T_{\mathrm{B}}\right)$ as well as immediately after $\left(T_{0}\right), 1$ hour after $\left(T_{1}\right)$, and 3 hours after SHS exposure $\left(T_{3}\right)$, with the data being collected at the same time of the day and without the effect of previous or subsequent measurements insofar as only one assessment was conducted per trial. Yet, our lung function results are limited by the impossibility of blinding our participants to SHS exposure. However, suggestibility does not appear to underlie acute physiological responses to SHS (35). Moreover, the present SHS-induced inflammatory reaction observed at $T_{0}$ was similar to a previous study by our group that incorporated a repeated measures-randomized block design with a sham SHS exposure (11), thus supporting our protocol. With these in mind, it is concluded that a 1-hour SHS exposure at levels similar to those of bars and restaurants is accompanied by significant decreases in lung function and marked increases in inflammatory cytokines, particularly in men. Importantly, although most SHSinduced effects on lung function appear to recede within 60 minutes, inflammatory cytokines remain elevated for at least 3 hours after SHS exposure.

Conflict of Interest Statement: None of the authors has a financial relationship with a commercial entity that has an interest in the subject of this manuscript.

\section{References}

1. U.S. Department of Health and Human Services. The health consequences of involuntary exposure to tobacco smoke: a report of the surgeon general; 2006. Atlanta, GA: U.S. Department of Health and Human Services, Centers of Disease Control and Prevention, Coordinating Center for Health Promotion, National Center for Chronic Disease Prevention and Health Promotion, Office on Smoking and Health.

2. Substance Abuse and Mental Health Services Administration. Results from the 2006 national survey on drug use and health: National findings (Office of Applied Studies, NSDUH series H-32, DHHS publication no. SMA 07-4293). Rockville, MD; 2007.

3. Mackay J, Eriksen M. The tobacco atlas. Geneva, Switzerland: World Health Organization; 2008.

4. Warren CW, Jones NR, Peruga A, Chauvin J, Baptiste JP, Costa de Silva V, el Awa F, Tsouros A, Rahman K, Fishburn B, et al. Global youth tobacco surveillance, 2000-2007. MMWR Surveill Summ 2008; 57:1-28.

5. Flouris AD, Faught BE, Klentrou P. Cardiovascular disease risk in adolescent smokers: evidence of a 'smoker lifestyle'. J Child Health Care 2008;12:217-227.

6. Siegel M. Is the tobacco control movement misrepresenting the acute cardiovascular health effects of secondhand smoke exposure? An analysis of the scientific evidence and commentary on the implications for tobacco control and public health practice. Epidemiol Perspect Innov 2007;4:12.

7. van der Vaart H, Postma DS, Timens W, Hylkema MN, Willemse BW, Boezen HM, Vonk JM, de Reus DM, Kauffman HF, ten Hacken NH. Acute effects of cigarette smoking on inflammation in healthy intermittent smokers. Respir Res 2005;6:22.

8. McGhee SM, Adab P, Hedley AJ, Lam TH, Ho LM, Fielding R, Wong CM. Passive smoking at work: the short-term cost. I Epidemiol Community Health 2000;54:673-676.

9. Churg A, Tai H, Coulthard T, Wang R, Wright JL. Cigarette smoke drives small airway remodeling by induction of growth factors in the airway wall. Am J Respir Crit Care Med 2006;174:1327-1334.

10. Widdicombe J, Lee LY. Airway reflexes, autonomic function, and cardiovascular responses. Environ Health Perspect 2001;109:579-584.

11. Metsios GS, Flouris AD, Jamurtas AZ, Carrillo AE, Kouretas D, Germenis AE, Gourgoulianis K, Kiropoulos T, Tzatzarakis MN, Tsatsakis AM, et al. A brief exposure to moderate passive smoke increases metabolism and thyroid hormone secretion. J Clin Endocrinol Metab 2007;92:208-211.

12. Flouris AD, Metsios GS, Jamurtas AZ, Koutedakis Y. Sexual dimorphism in the acute effects of secondhand smoke on thyroid hormone secretion, inflammatory markers and vascular function. Am J Physiol Endocrinol Metab 2008;294:E456-E462.

13. Sidorkewicz N, Carrillo AE, Metsios GS, Flouris AD, Jamurtas AZ, Koutedakis Y. Resting energy expenditure response following environmental tobacco smoke exposure. Med Sci Sports Exerc 2006;38: S457-S458.

14. Flouris AD, Metsios GS, Carrillo AE, Jamurtas AZ, Koutedakis Y, Tzatzarakis MN, Tsatsakis AM. Effects of passive smoking on resting and exercising humans. Can J Appl Physiol 2005;30:S28.

15. Mahmud A, Feely J. Effects of passive smoking on blood pressure and aortic pressure waveform in healthy young adults-influence of gender. Br J Clin Pharmacol 2004;57:37-43

16. Otsuka R, Watanabe H, Hirata K, Tokai K, Muro T, Yoshiyama M, Takeuchi K, Yoshikawa J. Acute effects of passive smoking on the coronary circulation in healthy young adults. JAMA 2001;286:436-441. 
17. Panagiotakos DB, Pitsavos C, Chrysohoou C, Skoumas J, Masoura C, Toutouzas P, Stefanadis C. Effect of exposure to secondhand smoke on markers of inflammation: the Attica study. Am J Med 2004;116:145-150.

18. Castro P, Legora-Machado A, Cardilo-Reis L, Valenca S, Porto LC, Walker C, Zuany-Amorim C, Koatz VL. Inhibition of interleukin1beta reduces mouse lung inflammation induced by exposure to cigarette smoke. Eur J Pharmacol 2004;498:279-286.

19. Kawachi I. More evidence on the risks of passive smoking. BMJ 2005; 330:265-266.

20. Yin P, Jiang CQ, Cheng KK, Lam TH, Lam KH, Miller MR, Zhang WS, Thomas GN, Adab P. Passive smoking exposure and risk of COPD among adults in China: the Guangzhou Biobank cohort study. Lancet 2007;370:751-757.

21. American Thoracic Society. Standardization of spirometry, 1994 update. Am J Respir Crit Care Med 1995;152:1107-1136.

22. Eisner MD, Wang Y, Haight TJ, Balmes J, Hammond SK, Tager IB. Secondhand smoke exposure, pulmonary function, and cardiovascular mortality. Ann Epidemiol 2007;17:364-373.

23. Ferguson GT, Enright PL, Buist AS, Higgins MW. Office spirometry for lung health assessment in adults: a consensus statement from the National Lung Health Education Program. Chest 2000;117:1146-1161.

24. Zach MS. The physiology of forced expiration. Paediatr Respir Rev 2000; $1: 36-39$.

25. Leuenberger P, Schwartz J, Ackermann-Liebrich U, Blaser K, Bolognini G, Bongard JP, Brandli O, Braun P, Bron C, Brutsche M, et al. Passive smoking exposure in adults and chronic respiratory symptoms (Sapaldia Study). Swiss study on air pollution and lung diseases in adults, Sapaldia team. Am J Respir Crit Care Med 1994;150:12221228.

26. Lee LY, Widdicombe JG. Modulation of airway sensitivity to inhaled irritants: Role of inflammatory mediators. Environ Health Perspect 2001;109:585-589.

27. Anderson R, Theron AJ, Richards GA, Myer MS, van Rensburg AJ. Passive smoking by humans sensitizes circulating neutrophils. Am Rev Respir Dis 1991;144:570-574.
28. Pauwels RA, Rabe KF. Burden and clinical features of chronic obstructive pulmonary disease (COPD). Lancet 2004;364:613-620.

29. Saetta M, Baraldo S, Corbino L, Turato G, Braccioni F, Rea F, Cavallesco G, Tropeano G, Mapp CE, Maestrelli P, et al. CD8+VE cells in the lungs of smokers with chronic obstructive pulmonary disease. Am J Respir Crit Care Med 1999;160:711-717.

30. Litonjua AA, Sparrow D, Guevarra L, O'Connor GT, Weiss ST, Tollerud DJ. Serum interferon-gamma is associated with longitudinal decline in lung function among asthmatic patients: the normative aging study. Ann Allergy Asthma Immunol 2003;90:422428.

31. Sin DD, Man SF. Commentary: fuelling the fire-systemic inflammation and development of lung disease in the general community. Int $J$ Epidemiol 2006;35:1008-1010.

32. Aronson D, Roterman I, Yigla M, Kerner A, Avizohar O, Sella R, Bartha P, Levy Y, Markiewicz W. Inverse association between pulmonary function and C-reactive protein in apparently healthy subjects. Am J Respir Crit Care Med 2006;174:626-632.

33. Pinto-Plata VM, Mullerova H, Toso JF, Feudjo-Tepie M, Soriano JB, Vessey RS, Celli BR. C-reactive protein in patients with COPD, control smokers and non-smokers. Thorax 2006;61:23-28.

34. Benowitz NL. Biomarkers of environmental tobacco smoke exposure. Environ Health Perspect 1999;107:349-355.

35. Urch RB, Silverman F, Corey P, Shephard RJ, Cole P, Goldsmith LJ. Does suggestibility modify acute reactions to passive cigarette smoke exposure? Environ Res 1988;47:34-47.

36. Peto R, Lopez AD, Boreham J, Thun M, Heath C Jr. Mortality from tobacco in developed countries: Indirect estimation from national vital statistics. Lancet 1992;339:1268-1278.

37. Towards a Europe free from tobacco smoke: policy options at EU level. A European Commission green paper [Internet]. Brussels: Commission of the European Communities; 2007. Com2007 27 final (Accessed 2008 Nov 2). Available from: http://ec.europa. $\mathrm{eu} / \mathrm{health} / \mathrm{ph}$ _determinants/life_style/Tobacco/Documents/gp_smoke_ en.pdf. 